\title{
A MULHER COMO PRODUTO DE SATISFAÇÃO MASCULINA NA PORNOGRAFIA: UMA ANÁLISE HISTÓRICO-SOCIAL
}

\author{
WOMEN AS A PRODUCT OF MALE SATISFACTION IN PORNOGRAPHY: A \\ HISTORICAL-SOCIAL ANALYSIS
}
Eloísa Amorim de Barros¹, Layâna Maria Araújo Machado², Mayara Gato de Sena Biá3, Rafaela Azevedo Guerreiro ${ }^{4}$

1 Curso de Psicologia do Instituto Esperança de Ensino Superior - IESPES, Brasil, e-mail: eamorimdebarros@gmail.com. ORCID: https://orcid.org/0000-0003-3599-2970

2 Curso de Psicologia do Instituto Esperança de Ensino Superior - IESPES, Brasil, e-mail: layyanamachado@gmail.com, ORCID: https://orcid.org/0000-0002-2759-0106

3 Curso de Psicologia do Instituto Esperança de Ensino Superior - IESPES, Brasil, e-mail: mayarabiaaa@gmail.com, ORCID: https://orcid.org/0000-0001-5073-7367

4 Curso de Psicologia do Instituto Esperança de Ensino Superior - IESPES, Brasil, e-mail: azevedoguerreirorafaela@gmail.com, ORCID: https://orcid.org/0000-0001-5336-6995

\author{
ARTICLE INFO \\ Article history: \\ Received 2020-06-01 \\ Accepted 2020-11-30 \\ Available online 2020-11-30
}

Palavras-chave: Pornografia. Mulher. Estereótipos. Feminismo.

Keywords: Pornography. Woman. Stereotypes. Feminism.

\begin{abstract}
RESUMO. O presente artigo, tem como proposta apresentar a percepção da sociedade brasileira sobre o que é "ser mulher", e sobre como esses estereótipos são reproduzidos nas mídias pornográficas, entendendo esse processo como uma construção social que acontece dentro de um sistema machista violento. A construção histórico-social do pornô foi descrita, englobando a era das revistas e fotografias, o avanço tecnológico com o cinema, o VHS, o DVD e, mais atualmente, a internet, podendo perceber o feminino sendo colocado nas mídias sempre de forma submissa e extremamente estereotipada. Além disso busca-se, também, apresentar um panorama das vertentes feministas que apoiam e reprovam a indústria pornográfica e como estas se posicionam com o fato de mulheres serem colocadas como produto comercializado para homens. Se caracteriza como um estudo bibliográfico, exploratório e descritivo, baseado em artigos científicos, livros e entrevistas relacionadas com a temática. Apesar de pouco ser discutido abertamente sobre a pornografia, ela é consumida por uma grande parcela da população e utilizada por muitos como "educadora sexual" sobre aqueles que não detém conhecimentos básicos em relação ao sexo. Já que em uma sociedade patriarcal, machista, misógina e sexista, dificilmente estas práticas serão reconhecidas como problemáticas para a vida das mulheres, em um meio que é voltado apenas para o prazer do público masculino. Por fim, é necessário que outras ciências, como a Psicologia, se apropriem ainda mais dessa discussão para que continue promovendo cuidado e suporte emocional para mulheres que vivenciam violências decorrente do machismo.
\end{abstract}

\begin{abstract}
The purpose of this article is to present the perception of Brazilian society about what "being a woman" means, and how these stereotypes are reproduced in pornographic media, understanding this process as a social construction that takes place within a violent sexist system. The socialhistorical construction of porn was described, encompassing the era of magazines and photographs, technological advances with cinema, VHS, DVD and, more recently, the internet, being able to perceive the female being placed in the media always in a submissive way and extremely stereotyped. In addition, it also seeks to present an overview of the feminist strands that support and disapprove of the pornographic industry and how they position themselves with the fact that women are placed as a product
\end{abstract}


marketed to men. It is characterized as a bibliographic, exploratory and descriptive study, based on scientific articles, books and interviews related to the theme. Although little is openly discussed about pornography, it is consumed by a large portion of the population and used by many as a "sex educator" for those who do not have basic knowledge about sex. Since in a patriarchal, sexist, misogynist and sexist society, these practices are unlikely to be recognized as problematic for women's lives, in a medium that is geared only to the pleasure of the male audience. Finally, it is necessary that other sciences, such as Psychology, take this discussion even more so that it continues to promote care and emotional support for women who experience violence resulting from machismo.

\section{Introdução}

Este artigo tem como objetivo apresentar discussões acerca da forma como a mulher é representada nas produções pornográficas, entendendo esse processo como uma construção social que acontece dentro de um sistema machista violento, que considera a mulher como alguém que tem uma única função: a de satisfazer. A motivação pela realização desta pesquisa está relacionada com a inquietação das autoras sobre a forma estereotipada com que a mulher continua sendo representada nos filmes pornôs, mesmo após tantas evoluções no que tange a luta feminina por igualdade de gênero e vivência plena da sexualidade.

A indústria pornográfica transforma a excitação sexual em seu fator de renda, buscando obter lucro através do sexo explícito e sem tabus. Esta, por sua vez, produz conteúdos sexuais que disseminam estereótipos, nos quais o papel de sujeito está direcionado ao homem, enquanto a mulher é vista e apresentada como objeto sexual. Sendo assim, é comum que nos vídeos pornográficos a submissão feminina seja fetichizada, e a mulher seja vendida como produto usado apenas para a satisfação dos desejos masculinos, conforme descreve D'Abreu (2013). O mercado que se tornou extremamente lucrativo, chama cada vez mais a atenção de grandes empresas mundiais e envolve, além de filmes pornôs, também acessórios sexuais - os chamados sex toys.

Entende-se que esse mercado, ao ser construído direcionado, em sua maioria, ao público masculino, acaba por se tornar um reflexo sociocultural, replicando e reiterando uma sociedade que inferioriza e sexualiza corpos femininos. Desse modo, segundo Júnior (2006), os papéis sociais que estabelecem essa espécie de ciclo vicioso entre sociedade e pornografia se perpetuam, pois essa segunda legaliza os desejos e uma domesticação dos corpos talvez nunca encontrada antes pela primeira. Portanto, "[..] os atos de dominação sexual constituem o significado social do 'homem', e a condição de submissão do significado social da "mulher" (SANTANA, 2016, p. 67).

A pornografia alcança altos faturamentos e uma visibilidade significativa e, como acrescenta Júnior (2006), essa milionária indústria vem passando por uma evolução no que diz respeito a tecnologia. Atualmente, com os avanços da internet e a criação de sites voltados 
para o pornô, o mercado cresce alcançando valores bilionários e segue perdurando conteúdos de cunho machista, mesmo com a também constante evolução de produções pornôs dirigidas e produzidas por mulheres, bem como a ampliação de produções que representam a diversidade sexual. Logo, destaca-se o quanto a pornografia — desde o seu surgimento ainda fabrica de maneira ampla conteúdos destinados a agradar exclusivamente o público masculino heterossexual.

Contudo, após séculos de silenciamento das mulheres, atualmente a indústria pornográfica fomenta debates e divergências dentro das vertentes do movimento feminista. Pois, parte das mulheres envolvidas no feminismo são "pró-censura" e acreditam que a indústria pornô explora mulheres e objetifica seus corpos, reprime-as e as transforma em produto, afinal, “[...] formas de pornografia misógina são acusadas de causar danos físicos às mulheres e de diminuir-Ihes as oportunidades, liberdades e direitos" (SILVA, 2013, p. 157).

Em contrapartida, as feministas que são a favor de produções pornográficas, apoiam um novo conceito de pornografia que, no entanto, não seja focado no pornô "mainstream" direcionado ao protagonismo do homem branco, hétero - sua diferenciação do mainstream acontece pois, busca dar mais visibilidade para diferentes tipos corporais, de genitais, de identidades e de práticas sexuais, ou seja, divergem dos padrões impostos pela sociedade, aponta Santana (2016). Assim, este texto percorrerá o caminho que envolve concepções sobre o que é ser mulher no Brasil, seguido do desenvolvimento da indústria pornográfica e a relação com as produções feministas.

\section{Metodologia}

Quando aos procedimentos, esta pesquisa se configura como bibliográfico por fazer uma revisão de literatura acerca do tema proposto, utilizando-se de artigos, livros, revistas científicas e etc. para o embasamento do trabalho. Quanto aos objetivos, é descritiva, pois, segundo Gil (2002) pretende descrever características de determinada população ou fenômeno, neste caso a presença feminina na indústria pornográfica. $E$ ainda, considera-se exploratória por realizar uma investigação crítica e científica, construir hipóteses e envolver levantamentos bibliográficos e, de acordo com Gil (2002), apresentando como objetivo principal o aprimoramento de ideias. As bases de dados consultadas foram: Scielo, livros, matérias e entrevistas relacionadas a temática da pornografia e sua relação com a mulher.

\section{O que é "ser mulher" no Brasil?}

Historicamente, não somente o senso comum ditou o que é ser mulher. Teorias sobre a diferenciação das estruturas cerebrais entre homens e mulheres, bem como alguns livros 
que se tornaram best sellers, trouxeram ideias que reafirmavam que as diferenças entre o ser feminino e o ser masculino não eram apenas construções sociais ${ }^{1}$, sugerindo generalizações acerca de comportamentos, sexualidade, feminilidade, aparência, e etc. Por outro lado, especialistas como Gina Rippon, cientista e professora de Neuroimagem Cognitiva da Universidade de Aston (Birmingham) realizou estudos que comprovam que não existem diferenças cerebrais entre homens e mulheres e afirma e entrevista ${ }^{2}$ que "um mundo sexista produz cérebros sexistas". Portanto, as concepções sobre padrões femininos de ser, estão intimamente ligadas com as construções machistas que se perpetuam desde que o mundo é mundo.

Logo, o conceito do que é ser bela é ressaltado por Goellner (1999) que apresenta o corpo feminino como exposto e espetacularizado, tornando-se objeto de desejo e convivendo com as exigências estéticas que afirmam que um corpo só se torna bonito quando está em movimento, ou seja, as mulheres precisam buscar a todo custo um corpo escultural, corpo este baseado nos padrões midiáticos consumidos pela maior parte da população. A demanda de delineamento de um padrão corporal, sofre influência desde a Grécia antiga que tinha a concepção de perfeição corporal atribuída às estátuas gregas, passando pela estética dos meios de produção mais modernos como por exemplo, a fotografia e o cinema. Essas exigências atribuídas a mulher sobre seu corpo e seus modos de vida, são baseadas em construções e desejos exclusivamente criados em uma sociedade patriarcal, ou seja, podese inferir que, em sua maioria, tais exigências servirão para suprir uma demanda masculina de desejo.

Esses e outros estereótipos foram implantados no Brasil com a colonização européia, a partir da chegada dos portugueses neste território. Neves e Kauss (2011) apontam que as mulheres indígenas tiveram seus corpos objetificados e violentados pelos homens brancos, que se intitularam donos das terras e de seus habitantes. Dessa forma foi iniciado o processo de miscigenação brasileira, por meio de abusos sexuais. Essa miscigenação forçada e violenta perpetuou-se com a chegada dos africanos que foram escravizados no Brasil. Classificadas pela cor, a mulher branca tinha o papel de dona de casa, reprodutora e serva do marido, de outro estava a mulher negra, colocada em condição de escrava, era constantemente abusada pelos senhorios e trocada feito mercadoria. Lopes (2007, p. 4) diz que "[...] à mulher escrava era objeto sexual, ama de leite dos filhos da senhora, empregada

\footnotetext{
${ }^{1}$ Ver: GRAY, John. Os homens são de marte e as mulheres são de vênus. Brasil: Rocco, 1995. e BRIZENDINE, Louann. O cérebro feminino. Morgan Estrada / Broadway Books. 2006
}

\footnotetext{
${ }^{2}$ Ver: http://www.ihu.unisinos.br/78-noticias/596710-um-mundo-sexista-produz-cerebros-sexistas-entrevista-com-gina-rippon
} 
doméstica, gerando o ditado: Mulher negra é para trabalhar, mulata para fornicar e branca para casar".

Igualmente, o casamento também recebia e recebe grande influência do meio religioso - o qual detém domínio considerável sobre sociedade e sexualidade -, no Estado brasileiro, principalmente por parte da igreja católica. O cristianismo chegou ao Brasil em meados do século XVI, e impôs, a partir de uma visão medieval, um comportamento rígido que desaprovava as práticas sociais e sexuais nativas dos indígenas, aponta Silva (2008). Sendo assim, a igreja pregou a ideia de que a castidade feminina remetia à pureza — privando mulheres de exercerem práticas sexuais - e caso as fizessem, atribuíam-nas ao pecado. No entanto, em contradição, Marzochi (2003) destaca que a mulher na antiguidade era considerada símbolo de desejo sexual, ideia essa ainda presente na atualidade, fazendo com que desde crianças as mulheres já atraiam olhares hiperssexualizados.

A cultura que contribui para a hiperssexualização feminina e para que meninas assumam a condição de serem objetos sexuais se soma às imposições religiosas e, segundo Scavone (2008), faz com que a problemática seja ainda maior, pois, a existência de uma hierarquia católica masculina, que dita regras também para as mulheres, reforça e perpetua a desigualdade de gênero. Dessa forma, o homem desde sempre se constituiu como figura dominante nas relações - conjugais, paternas, trabalhistas - enquanto a mulher ocupou e continua ocupando lugares voltados unicamente para a subordinação, constituindo assim patriarcado.

Dito isso, observamos o quanto a figura feminina foi, e é estabelecida como "objeto de serviço" caseiro e sexual durante todo o contexto histórico-social brasileiro. Voltada unicamente à uma vida doméstica e erótica, ambas determinadas por homens que delimitam como essas mulheres devem ser, se comportar, agir, falar, entre outros. Estes personificam cada detalhe e também criam preferências de biotipos corporais. Boris e Cesídio (2007) afirmam que a constituição do corpo e da subjetividade da mulher são baseados na sociedade e no período histórico em que vivem. Os autores ressaltam que a maneira como as mulheres organizam seus modos de ser e existir no mundo também foram e são influenciadas pelas transformações econômicas, políticas, históricas e socioculturais. Dessa forma, mesmo que os modos de viver femininos tenham sido modificados no decorrer da história do Brasil baseados em transformações que possibilitaram o acesso a direitos básicos que antes não tinham, como trabalhar ou votar, pode-se afirmar que ainda há um longo caminho pela frente.

Toda essa trajetória de subordinação gerou efeito de encorajamento e luta constante para milhares de mulheres pelo Brasil, em busca de representatividade, equidade e igualdade social, pois, mesmo com todos os avanços, ainda vivemos em uma sociedade machista. Diante disso, cabe aqui ressaltar que, segundo o dicionário Dicio (2009), machismo significa 
"opinião ou atitudes que discriminam ou recusam a ideia de igualdade dos direitos entre homens e mulheres.", estando a cultura brasileira compenetrada nesse patriarcalismo sistêmico desde o período colonial. Sendo assim, Venturini e Godinho (2013) descrevem que não há exagero nenhum em dizer que o Brasil é um país machista, na forma mais brutal de dominação masculina.

A construção social de subordinação feminina está em todos os âmbitos da sociedade, um deles são as produções pornôs que se utiliza da ideia de que a mulher tem como função proporcionar o prazer masculino, a todo custo. Desse modo, a indústria pornográfica se consolidou no mercado e lucra bilhões a partir da exploração de corpos femininos.

\section{Desenvolvimento da Indústria Pornográfica: da fotografia à internet}

Compreende-se que o ser humano está diretamente ligado aos avanços tecnológicos, e assim se adapta ao facilitado acesso à informação que lhe são disponibilizados no decorrer do tempo. Dito isso, a pornografia foi se adequando às diversas realidades sociais, se "aprimorando". No entanto, assim como avançamos, também permanecemos no conservadorismo, como destacam Venturi e Godinho (2013), pois, neste mercado a mulher permanece sendo posta de maneira inferiorizada, como uma mercadoria sexual de submissão, e ainda, estereotipada a partir de uma visão eurocêntrica.

Tendo em vista que, o Brasil recebe influências estrangeiras, Azevedo e Junior (2017, p. 144) afirmam que "[...] precisamos recorrer a um contexto ocidental mais amplo que trate de jornais e livros pornográficos europeus, uma vez que há uma clara influência destes na composição dos impressos brasileiros". Logo, com o avanço da globalização e a introdução à literatura, os perfis femininos apresentados nas revistas pornôs brasileiras remetiam à mulheres brancas, loiras e de olhos claros.

Por conseguinte, no final do século XX ocorre o surgimento da internet e o pornô entra no mercado virtual. Logo, através dos avanços nas redes, o envolvimento com as mídias sociais, se bem administrado é seguido por popularidade e visualizações, se tornando um mercado ainda mais lucrativo, que tem como sua principal fonte de lucro o imaginário social que envolve as práticas sexuais que sempre foram vistas como um tabu.

No Brasil, no contexto original, pornografia significava "histórias de prostitutas" ressalta Mendes (2016). No entanto, com o final do século XIX surgem os impressos com representações sexuais, e então o nome "pornografia" passou a ser popularizado. Outrossim, as livrarias da época, em seus anúncios a nomeavam de "livros para homens". 
Ademais, havia o jornal "O Rio Nu", o qual era publicado bissemanalmente, entre os anos de 1898 e 1916. Os autores Azevedo e Júnior (2017, p. 145) relatam que "o jornal era composto por quatro páginas, sem imagens, mas com textos voltados para o humor por meio da pornografia". Com isso, havia uma variedade de conteúdos, que partia de contos eróticos, poemas a um modo sarcástico de dar as notícias, como nas categorias de jogos, loteria, críticas, e etc. Assim, os jornais eram produzidos em meio à um teor pornográfico e humorístico.

Giordano (2012) descreve algumas revistas pornôs que surgiram a partir da segunda metade do século XX, e foram sucesso no Brasil: revista "Fairplay: a revista do homem" em 1966; a revista "Playboy" - uma das mais populares na indústria erótica - em 1975; e também em 1975 eclode "A revista do homem". Observa-se que mesmo com essa passagem de praticamente um século, o conceito pornográfico pouco mudou, pois, segue reconhecido como entretenimento voltado unicamente para homens. Desta forma, as revistas "[...] representam mulheres fetichizadas, produzidas por fotógrafos homens, e, muitas vezes, destinadas ao público masculino." de acordo com (BOTTI, 2003, p. 111). Demonstrando assim, que a visão de "mulher ideal" passada para a sociedade através da pornografia, é atribuída inteiramente para agradar os homens.

Logo, não é apenas o conteúdo pornográfico que delimita essa visão patriarcal, pois muitas revistas voltadas ao sexo feminino também publicavam conteúdos machistas. Assim, podemos observar essa propagação do machismo através da revista "EleEla - uma revista para ler a dois" com sede no Rio de Janeiro e publicada pela Bloch, do ano de 1969. Visto que, quando esta passou a ter mais conteúdos voltados às mulheres, começaram a aparecer manchetes de teor conservador, como: "Até que ponto posso ficar nua" e "O fino da conquista". Com isso, como descrito por Júnior (2006), conclui-se que, quando a indústria passa a se introduzir no mercado abertamente, expande seu produto, e ao ser aceita, reforça as influências midiáticas a lhe seguirem, fortalecendo um senso comum arcaico.

Marzochi (2003) descreve que q partir da era da globalização e com o crescimento acelerado da tecnologia no século $\mathrm{XX}$, há um intenso avanço tecnológico nos meios de: fotografia, cinema e televisão na década de 50; internet e meios de comunicação digitais, na década de 90. Assim ocorre uma "explosão do erotismo". Diante disso, estudos de Bercht (2019) apontam para um aumento da comercialização da pornografia e, consequente aperfeiçoamento das produções, nas quais a imagem da mulher continua sendo amplamente utilizada, e a propagação de estereótipos corporais continua sendo cada vez mais fortalecida. Desta forma, o mercado pornográfico dissemina discriminação sexual, subordinação feminina, e também sobre essas, efeitos de silenciamento. 
Não se sabe onde o primeiro pornô cinematográfico foi feito, no entanto, muitos destes iniciaram sendo produzidos em Buenos Aires, em meados de 1904, relata Kämpf (2008). A autora afirma que a partir disso, a produção foi apenas crescendo, e se expandindo cada vez mais para os cinemas do mundo, ganhando popularidade, houve o aumento da rotatividade do dinheiro nas linhas de produção. Além disso, os bordéis passaram a reproduzir esses filmes, e, logo, bordéis de elite também passaram a exibi-los, dando início a uma grande comercialização da cultura pornográfica, nessa época, ainda mais com as classificações de faixa etária sendo implantadas. Após isso, acontecem mais avanços, e nos anos 1980 surge o videocassete, o que facilitou o consumo, pois as pessoas agora contavam com a facilidade de assistir os filmes no conforto de suas casa.

O resultado dessa facilidade também proporcionou a evolução das câmeras de vídeo, o que permitiu a produção de filmes caseiros chamados de "pornô amador". Assim "com o advento do vídeo caseiro, o status precário da narrativa no filme pornô é intensificado." (KÄMPF, 2008, p. 52), deixando de ser um filme, e passando a ser chamado de 'vídeo', porque passa a ter um corte mais direto voltado para o sexo e não incorpora mais uma história cheia de narrativa e nudez". Por conseguinte, o advento do DVD e da internet, facilitou ainda mais o acesso às produções.

Contudo, nesse período se começou a pensar que o pornô poderia ser assistido por pessoas que não fossem apenas homens héteros. Como descrevem os autores Pinto, Nogueira, e Oliveira (2010) os padrões tradicionais seguidos para agradar o público heterossexual foram deixando de ser o único alvo da pornografia, assim, expandindo o mercado à possibilidades alternativas, logo, os vídeos passaram a abranger um público maior, aumentando a variedade de sites com conteúdos pornográficos e, consequentemente os acessos a eles. Sendo assim, a qualquer hora, seja qual for o fetiche, a era digital permite que os desejos sejam saciados com apenas alguns "cliques", proporcionando grande facilidade para que se possa encontrar uma diversidade de materiais.

Mesmo com todas as mudanças, tanto tecnológicas quanto no que se refere ao público consumidor desse tipo de produção, as mulheres continuam sendo postas em situação de submissão frente aos fetiches masculinos e com estereótipos sendo reproduzidos. Portanto, além de colocar o ato sexual como uma condição desprezível para a figura feminina - nos filmes e vídeos —, esses fetiches, ao passarem a ser experienciados pelos consumidores, privam as mulheres do prazer sexual, destaca Bercht (2016), que, muitas vezes, toleram tais situações para agradar os seus parceiros. O que nos remete, mais uma vez, aos estereótipos de dominação masculina e obediência feminina, imposto pela pornografia que, sendo um produto da sociedade, reforça os papéis de gênero nela estabelecidos. 


\section{Feminismo (s) e a Pornografia: relações possíveis}

Como dito anteriormente, as produções dos filmes pornôs eram voltadas unicamente para os homens, assim, priorizando os seus prazeres, gostos e ideais. Como ressaltam Santana e Rubim (2017, p. 639) a "Testosterona é o combustível principal para a indústria pornográfica". Em uma sociedade na qual a voz ativa ainda é masculina, apesar das mudanças que estão ocorrendo na sociedade, o sistema patriarcal que estrutura as relações ainda se sobrepõe em diversos espaços, reforçando assim o lugar de inferiorização e subordinação em que as mulheres são colocadas, assim, não seria diferente no contexto do mercado pornográfico.

Visto isso, é válido ressaltar o início de uma mobilização político-social feminina, denominado feminismo. O feminismo, em sua prática, busca desarticular as formas tradicionais de "organização" patriarcal, buscando acabar com a desigualdade de gênero e imposições e estereótipos machistas. Outrossim, dentro do movimento, se estabelecem grupos com demandas específicas, chamadas vertentes feministas, as quais buscam a união feminina, equidade, sororidade e etc., como destacam Alves e Pitanguy (2017).

Diante disso, Bercht (2016, p. 7) descreve que os filmes pornográficos “[...] promoviam a objetificação da figura feminina e impulsionaram, desta forma, a violência contra a mulher em seus diversos níveis." Deste modo, durante o século XX, lutas feministas foram ganhando espaço na sociedade e ainda tentam, com dificuldades - mas também com avanços vencer o machismo, o sexismo e a misoginia, que estão enraizados tanto na sociedade quanto no pornô.

Assim, a partir das vertentes feministas e seus respectivos objetivos, duas se contrastam em relação à pornografia. Uma delas apoia e produz em massa vídeos pornôs que atingem grande popularidade. Chamada de "feminismo pró-sexo", diferentemente do pornô "mainstream", esta seria a abertura do mercado pornográfico para diversidade e empoderamento feminino. Ou conforme explica Santana (2016, p. 86) é a "[...] pornografia, com objetivo de abrir espaço para diferentes expressões e representações de sexualidade e desejos.".

Logo, é importante validar que, a pornografia "mainstream" é a mais popularizada entre os famosos sites de pornô, sendo esta produzida por homens e direcionada para homens, contemplando os fetiches masculinos e desconsiderando os prazeres femininos. Em contrapartida, surgiu a corrente feminista denominada "feminismo pró-sexo", originada por militantes favoráveis à liberdade sexual da mulher, gerando então a pornografia feminista, voltada para mulheres. Abrindo um espaço alternativo dentro da indústria, esta foi criada com 
o intuito de se diferenciar do saturado pornô mainstream, de prevalência heterossexual (PINTO, NOGUEIRA E OLIVEIRA, 2010). Assim, a pornografia feminista surgiu com o objetivo de produzir um conteúdo que busque promover a emancipação feminina.

Desse modo, formou-se no cenário uma produção de filmes feitos unicamente por mulheres, como exemplifica Santana (2016), Candida Royale ao criar a "Femme Productions" teve grande destaque com a produção de filmes pornôs direcionados ao público feminino heterossexual. Visando uma forma de inclusão ativa de mulheres no contexto da pornografia. Além de trazer o benefício da liberdade para as mulheres doutrinadas pelo patriarcado, essas produções também podem fazer com que "(re)pensem" seus desejos sexuais, assim quebrando os paradigmas impostos pela sociedade, servindo inclusive para que mulheres conservadores pudessem refletir sobre suas formas de vivenciar sua sexualidade.

Em contrapartida, existe outra intensa luta - também feminista - que se contrapõe às normatizações do pornô tradicional, o qual objetifica e explora as mulheres. Santana e Rubim (2017) apontam que as principais discussões giram em torno das formas como as mulheres podem alcançar a liberdade sexual e de como as práticas sexuais poderiam ser opressoras ou emancipadoras. As autoras afirmam que se viu uma porta aberta para o debate sobre a sexualidade, espaço para representatividade, liberdade sexual da própria mulher, entre outros. Porém a oposição das anti-pornografia ocorre pelo uso equivocado que se tem do produto, pois, a pornografia feminista, por mais que tente produzir vídeos que mostrem mais da realidade feminina, acaba comercializando corpos da mesma maneira e consequentemente, cria novos padrões.

Por fim, acaba-se formando uma nova variedade de fetiches que, novamente, agrada aos homens. Santana (2016) destaca que essa proposta de produzir pornografia a partir da "perspectiva feminina" retorna ao pornô tradicional, de maneira que o "pornô feminista" também acaba reproduzindo outros estereótipos de feminilidade. Ou seja, a pornografia rejeita o prazer sexual feminino e transforma o sexo em uma "performance" para a mulher.

Visto isso, as relações sexuais podem se tornar desprazerosas para as mulheres, pois, incentivadas pelo pornô, reproduzem as performances apresentadas nos filmes, desconsiderando seu próprio prazer, em busca da satisfação do parceiro.

\section{Considerações Finais}

Diante do exposto, foi possível apresentar uma breve reflexão sobre a grande influência que o meio pornográfico tem sobre o indivíduo, podendo-se observar os vários tipos de 
autoritarismo presente nesse conteúdo, que acaba determinando como devem ser as relações sexuais e qual o padrão de feminilidade considerado ideal.

A evolução das tecnologias acontece de forma cada vez mais rápida, o universo da pornografia acompanhou esse crescimento e se estabeleceu nas mídias sociais, que varia de revistas a internet. Esse mundo cibernético vem apoderando-se, e apenas com pequenas palavras em uma simples pesquisa se encontra uma variedade de produções que apresentam as mais variadas formas de suprir necessidades e fetiches. Por um lado, existe a facilidade de se encontrar o prazer instantâneo, por outro em grande parte dessas produções a mulher continua sendo usada unicamente para a satisfação masculina.

Assim, pode-se constatar que na contemporaneidade a população feminina continua sofrendo opressão do sistema patriarcal, o que consequentemente é refletido nas produções pornográficas, que usam a imagem feminina de maneira estereotipada e objetificada, resultando em um tratamento desrespeitoso dos homens em relação a elas. Alguns relatos sobre a objetificação feminina e a violência que as próprias atrizes vivenciam nas gravações de filmes e vídeos pornôs, comprovam que o caminho a ser percorrido para a minimização das mais variadas formas de violência contra a mulher, inclusive na pornografia, ainda é longo ${ }^{3}$. Visto isso, os relacionamentos podem se tornar desagradáveis e causadores de danos psicológicos para as mulheres, que se sentem na obrigação de serem somente fontes de prazer para seus parceiros.

Pôde-se observar a tentativa das criações pornográficas voltadas para mulheres, através do pornô feminista, que tentam encontrar um meio de se sentirem representadas em um universo machista e misógino. Entretanto, a pornografia feminista, por mais venha produzindo vídeos que apresentam a realidade feminina em um outro formato, acaba comercializando corpos da mesma maneira e consequentemente, criando novos padrões. Assim, as próprias mulheres acabaram criando novos estereótipos de feminilidade, visto que, há uma vasta subjetividade de gostos, corpos e personalidades

Em suma, a partir do exposto foi possível observar a ascensão do mercado pornográfico, notando o quanto as mulheres ainda sofrem diversas explorações físicas e psicológicas dentro e fora desta indústria, sendo transformadas em “objetos" lucrativos. Deste modo, é possível refletir sobre as mudanças necessárias e significativas que deveriam ocorrer dentro deste cenário, por mais que ocorra de modo gradual e lento.

Portanto, é extremamente necessário que o fato da mulher ser vendida como produto no mercado pornográfico seja cada vez mais exposto e discutido em toda a sociedade, através

\footnotetext{
${ }^{3}$ Ver : TV USP. Mulheres no Filme Pornô - PGM 04. 2014. (11m50seg). Disponível em: <https://www.youtube.com/watch?v=hIokmr12P0\&feature=emb_title\&has_verified=1> Acesso em: 29/05/2020.
} 
de produções científicas e de ações que promovam a para que mais mulheres se apropriem da discussão e busquem também promover mudanças na sociedade e, consequentemente nas produções pornográficas. Apesar de pouco ser discutido abertamente sobre a pornografia, ela é consumida por uma grande parcela da população e utilizada por muitos como "educadora sexual" sobre aqueles que não detém conhecimentos básicos em relação ao sexo. Já que em uma sociedade patriarcal, machista, misógina e sexista, dificilmente estas práticas serão reconhecidas como problemáticas para a vida das mulheres, em um meio que é voltado apenas para o prazer do público masculino. Por fim, é necessário que outras ciências, como a Psicologia, se apropriem ainda mais dessa discussão para que continue promovendo cuidado e suporte emocional para mulheres que vivenciam violências decorrente do machismo, que insiste em continuar nos matando e matando também o nosso prazer.

\section{Referências}

ALVES, Branca Moreira; PITANGUY, Jacqueline. O que é feminismo. São Paulo: Brasiliense, 2017.

AZEVEDO, Natanael; JÚNIOR, José Ferreira. Pornografia e literatura: uma história pelo buraco da fechadura. Revista Graphos. v. 19, n. 2, p. 140-164, 2017. Disponível em: <https://doi.org/10.22478/ufpb.1516-1536.2017v19n2.37690>. Acesso em: 05 out. 2019.

BERCHT, Gabriela. Pornografia e atos de fala: o debate entre Judith Butler e Catharine MacKinnon. Porto Alegre, 2016. Trabalho de Conclusão de Curso de Graduação (curso de Filosofia: Bacharelado) - Universidade Federal do Rio Grande do Sul. Disponível em: <https://www.lume.ufrgs.br/handle/10183/156949 >. Acesso em: 05 out. 2019.

BORIS, Georges Daniel Janja Bloc; CESÍDIO, Mirella de Holanda. Mulher, corpo e subjetividade: uma análise desde o patriarcado à contemporaneidade. Revista Mal-Estar e Subjetividade, v.7, n.2, Fortaleza, 2007. Disponível em: < http://pepsic.bvsalud.org/scielo.php?script=sci_arttext\&pid=S1518-61482007000200012>. Acesso em: 30/06/2020.

D'ABREU, Lylla Cysne Frota. Pornografia, desigualdade de gênero e agressão sexual contra mulheres. Psicologia \& Sociedade, Belo Horizonte , v. 25, n. 3, p. 592-601, 2013 . Disponível em: <https://doi.org/10.1590/S0102-71822013000300013>. Acesso em: 11 ago. 2019.

GIL, Antonio Carlos. Como elaborar projetos de pesquisa. São Paulo: Atlas, 2002.

GIORDANO, Verônica. Negócios, política e sexo - A revista Playboy do Brasil 1975-80.

Revista USP. n. 95. p. 150-158, set./out./nov., 2012. Disponível em: $<$ http://www.revistas.usp.br/revusp/article/view/52247/56284>. Acesso em: 06 out. 2019.

GOELLNER, Silvana Vilodre. Imperativos do ser mulher. Motriz. v. 5, n. 1, p. 40-42, jun. 1999.

Disponivel em: 
$<$ http://www.periodicos.rc.biblioteca.unesp.br/index.php/motriz/article/view/6641>. Acesso em: 20 jun. 2019.

JÚNIOR, Jorge Leite. Das maravilhas e prodígios sexuais: a pornografia" bizarra" como entretenimento. 1. ed. São Paulo: Annablume, 2006.

KÄMPF, Raquel. Para uma estética na pornografia. Palhoça, 2008. Disponível em: $<$ https://www.riuni.unisul.br/handle/12345/4614>. Acesso em: 10 ago. 2019.

LOPES, Helena Theodoro. Mulher negra, mitos e sexualidade. In: Simpósio internacional o Desafio da diferença articulando gênero, raça e classe. Salvador, 2007. Disponível em: <http://www.desafio.ufba.br/gt6-005.html>. Acesso em: 06 out. 2019.

MARZOCHI, De Luca Marcelo. Pornografia na internet. Revista de Direito Administrativo. v. 233, p. 229-243, jul./set., 2003. Disponível em: $<$ http://bibliotecadigital.fgv.br/ojs/index.php/rda/article/view/45450>. Acesso em: 06 out. 2019.

MENDES, Leonardo. Livros para homens: sucessos pornográficos no Brasil no final do século XIX. Cadernos do IL. n. 53, p. 173-191, jan., 2016. Disponível em: <https://seer.ufrgs.br/cadernosdoil/article/view/67571>. Acesso em: 14 ago. 2019.

NEVES, Kelly Cristina da Silva; KAUSS, Vera. Reflexões sobre as representações da muIher indígena na sociedade brasileira. E-scrita: Revista do Curso de Letras da UNIABEU. v. 2, n. 5, p. 78-90, mai./ago., 2011. Disponível em: $<$ https://revista.uniabeu.edu.br/index.php/RE/article/view/184>. Acesso em: 20 jun. 2019.

NUNES, Ébano. O Cinema Obsceno em Conflito: a história diante das fontes de pornografia e erotismo. Cadernos do Tempo Presente. n. 17, p. 55-60, set./out., 2014. Disponível em: <seer.ufs.br>. Acesso em: 05 out. 2019.

PINTO, Pedro; NOGUEIRA, Maria da Conceição; OLIVEIRA, João Manuel de. Debates feministas sobre pornografia heteronormativa: estéticas e ideologias da sexualização. Psicologia: reflexão e crítica. v. 23, n. 2, p. 374-383, 2010. Disponível em: $<$ https://www.scielo.br/scielo.php?pid=S0102-

79722010000200020\&script=sci abstract\&tlng=pt>. Acesso em: 29 mai. 2020.

SANTANA, Camilla Martins. Da pornografia à pornoteoria: desafios e reimaginações feministas. Brasília, 2016. Disponível em: <https://repositorio.unb.br/handle/10482/20009>. Acesso em: 11 ago. 2019.

SANTANA, Léa Menezes de; RUBIM, Lindinalva da Silva. Feminismo e pornografia: distanciamentos e aproximações possíveis. 2017. Disponível em: $<$ http://www.ufpb.br/evento/index.php/17redor/17redor/paper/view/349>. Acesso em: 06 out. 2019. Acesso em: 03 out. 2019.

SCAVONE, Lucila. Estudos de gênero: uma sociologia feminista?. Revista Estudos Feministas. v. 16, n. 1, p. 173-288, jan-abr., 2008. Disponível em: $<$ https://periodicos.ufsc.br/index.php/ref/article/view/S0104-026X2008000100018>. Acesso em: 03 out. 2019.

SILVA, José Amilton da. O olhar das religiões sobre a sexualidade. 2008. Disponível em: $<$ http://www.diaadiaeducacao.pr.gov.br/portals/pde/arquivos/728-4.pdf >. Acesso em: 21 jun. 2019. 
SILVA, Júlio César Casarin Barroso. Liberdade de expressão, pornografia e igualdade de gênero. v. $21, \quad$ n. 1 , p. 143-165, jan/abr., 2013. Disponível em: $<$ https://www.scielo.br/pdf/ref/v21n1/08.pdf>. Acesso em: 03 out. 2019.

TEIXEIRA, Filomena. Hipersexualização, género e media. Revista Interacções. v. 11, n. 39, p. 1-9, 2015. Disponível em: <https://revistas.rcaap.pt/interaccoes/article/view/8718>. Acesso em: 05 out. 2019.

VENTURI, Gustavo; GODINHO, Tatau (Ed.). Mulheres brasileiras e gênero nos espaços públicos e privado - Uma década de mudanças na opinião pública. 1. ed. São Paulo, Fundação Perseu Abramo. 2013. 